International Journal of Translation \& Community Medicine (IJTCM)

ISSN 2333-8385

\title{
The Fecundity of the Race Discourse in Public Health and Epidemiology : Understanding the Limits of Explaining Health Disparities Using Race Categories in Brazil
}

Nene Ernest Khalema ${ }^{1,2,3 *}$

${ }^{1}$ Adjunct Professor of Public Health, Centre for Health Promotion Studies, School of Public Health, University of Alberta, Canada.

${ }^{2}$ Senior Research Specialist, Human and Social Development, Human Sciences Research Council, Durban, 4001, South Africa.

${ }^{3}$ Research Associate, School of Built Environment \& Development Studies, University of KwaZulu-Natal, South Africa

\begin{abstract}
This paper problematizes the use of race categories in epidemiological and health surveys in Brazil. The (re)production of epidemiological data using racial categories is common practice in epidemiology and public health. Often presented as a means of explaining the persistence of gaps in health status across diverse groups, racial categories have enjoyed an uncritical advantage. The rationale of using racial categories in surveys by its proponents is that such categories facilitate the development of policies that address structural inequalities in health access, and foregrounding reasons why disparities in health outcomes for minoritized and racialized groups and how broader social determinants of health (SDOH) must be addressed. Justified by the persistence of poorer health outcomes for minoritized groups in pluralistic societies, health researchers often argue for the necessity to collect data using racial categories. Utilizing the Foucauldian inspired Critical Discourse Analytic (CDA) method, this paper comments on the data quality issues related to the use of racial categories and the methodological dilemma such a practice poses for public health researchers and epidemiologists. The paper further cautions that an uncritical use of racial categories in public health surveys, reinforce and perpetuate a sense that the measures are real, their meaning uncomplicated, and their properties substantial.
\end{abstract}

Keywords: Race; Quantitative Epidemiology; Brazil; Health Disparities; Racial Classifications; Critical Discourse Analysis; and Public Health.

\section{*Corresponding Author:}

Nene Ernest Khalema PhD,

Senior Research Specialist, Human and Social Development, Human Sciences Research Council, Durban, 4001, South Africa and Adjunct Professor of Public Health, Centre for Health Promotion Studies, School of Public Health, University of Alberta, Canada.

Tel: +27834098805

Fax: +27312425401

E-mail: ekhalema@hsrc.ac.za and ekhalema@ualberta.ca

Received: August 19, 2015

Accepted: October 12, 2015

Published: October 14, 2015

Citation: Nene Ernest Khalema (2015) The Fecundity of the Race Discourse in Public Health and Epidemiology: Understanding the Limits of Explaining Health Disparities Using Race Categories in Brazil. Int J Translation Community Dis. 3(4), 71-78. doi: http://dx.doi. org $/ 10.19070 / 2333-8385-1500013$

Copyright: Nene Ernest Khalema ${ }^{\mathcal{O}} 2015$. This is an open-access article distributed under the terms of the Creative Commons Attribution License, which permits unrestricted use, distribution and reproduction in any medium, provided the original author and source are credited.

\section{Introduction}

Over the last decade, there has been a deepening debate in epidemiology and public health about the use of racial categories in researching health outcomes for diverse population groups. A plethora of studies have sprung up to position "race" as a culprit that explains health disparities amongst diverse population worldwide $[17,24-26,33,36]$. Global, national, and local epidemiological reports explaining health disparities have generated interesting knowledge about disparities in health outcomes based on "race." Some of this is evidenced by the World Health Organization`s (WHO) efforts to implement equity initiatives aimed at addressing disparities at a global scale $[47,48]$. Increasing public attention on the matter and advocacy for greater interventions have also advanced the discourse to a point at which nation states are urged to collect surveillance data using "race" or ethnicity as variables [32]. Whether these disparities are theorized as social disparities or biological, or even genetic differences, "race" is being promoted as consequential to health disparities and thus policies that governments and state institutions pursue (from public health interventions to funding for medical research to services healthcare practitioners offer their clients or advocate for the public) should take measure of it. This research agenda not only reveals how "race" is conceptualized in epidemiology and medicine, but also how it impacts everyday understandings of "race" and how "race" is framed in relation to other social welfare agendas such as funding public health programs, health promotion initiatives, and strategic health research. As such, the field of epidemiology and public health convincingly utilises racial categories to explain the connection between stratification and health disparities; documenting health patterns and differential outcomes including substantial and persistent health disparities between population groups. Additionally, the persistence of poorer health outcomes for diverse groups raises the spectre of the usual suspects: a lack of truly equal access to good healthcare and a breakdown in ef- 
fective interactions between racialized groups and the health care system. These factors indicate the importance for using racial categories as a marker of difference, especially in epidemiology and public health.

This research paper discusses limits and justifications related to the reification of "race" and discuss methodological dilemmas in measurement, conceptualization of the findings, and application in public health and community medicine praxis. Employing a critical discourse analytical (CDA) method, this paper examines the utilization of racial categories in three public health surveys in Brazil. Specifically, the paper analyzes the content, language, and structure of the 2003 World Health Survey (WHS), the 2006 Brazilian National Household Sample Survey (BNHSS) and the Brazilian Oral Health Survey (BOHS) as examples to demonstrate that when "race" is narrowly conceptualized, differences in values regarding health behaviors of individuals and groups are often ignored and silenced. Thus, the technology of epidemiological enumeration and the knowledge it produces is shaped by all kinds of narratives, positions, and assumptions that must be underlined and exposed to refine and reexamine research praxis. Therefore, in practice quantitative epidemiological discourse(s) of "race" normalize classification systems of "race" in particular ways for specific purposes, pointing to the construction, and regurgitation of a discourse in the research process. This paper cautions against an uncritical use of "race" categories in epidemiological research explaining health disparities, thus reinforcing a sense that the measures are real, the properties of racialized categories important, and their meaning unproblematic.

\section{Data Sources, Methods \& Analysis}

The method of Critical Discourse Analysis $(\mathrm{CDA})^{1}$ as articulated by Foucault (1972, 1981), van Dijk (1995, 1997), Fairclough \& Wodak's (1997), and Carabine (2001) stipulate an assessment of how knowledge produced and why it is produced. For van Dijk (2001) CDA is a type of discourse analytical research that primarily studies the way social power abuse, dominance, and inequality are enacted, reproduced, and resisted by text and talk in the social and political context. Thus, the overriding objective of CDA, according to Fairclough (2000), is to give accounts of the ways in which social discourse (re)constructs" social life in different ways for particular reasons. The analysis that informs this paper was guided by the overarching research question: "bow are the prevailing discourses on "race" and bealth disparity taking shape in Canada and Brazil and what are their implications for global health research, policy, and practice"?, Carabine's (2001) recursive steps for CDA that includes an analysis of prevailing discourses on the link between race and health disparities, how this link is conceptualized in epidemiology, and how discourses produced by researchers about the link are operating contextually (i.e. are they accepted, resisted, or transformed), and what the effects and limitations of the discourse are within a broader context was adopted as mode of analysis. To offer a more detailed analysis of the surveys, the analysis emphasized three levels of analyses: (a) a description of the material including content, language used, and structure; (b) the possible messages and impact of the content, language used, and structure; and (c) the socio-political analysis, including power, dominance, and institutional practices that validate "everyday" racialization discourse [13]. These analytical strategies seek to expose how race is enacted, reproduced, and to a certain degree resisted [38]. The idea was to point to the discursive strategies that normalize race talk as a necessary precondition for explaining health disparities and how the discourses about the link of race to health disparities are kept in place and circulated through research practices of survey enumeration, data comparison and racial classification. Furthermore, the CDA of the three surveys was conducted to highlight "absences, silences, and contradictions" in the information produced; and aims at "illuminating resistances and counter-discourses" by "identifying the effects of discourse" through an analyses of the implications of discourse in terms of how power and knowledge are valued and circulated [8]. These strategies also allows a deeper analyses of overt and covert messages in secondary analyses derived from the use of "race" utilizing national survey and postulate their impact in (re) producing discourses about "race." Thus, situating the analysis in the broader discursive context of research terrain" and attending

Figure 1. Carabine' (2001) Recursive Steps for Critical Discourse Analysis (CDA).

1. Getting to know the data: " $[1$ read and reread literacy-advice texts as I collected them, often searching out data that had intertextual relationships to those already collected" (p. 45).

2. Identifying themes: "The process of identifying themes was embedded in the reading and rereading of advice" (p. 46).

3. Looking for evidence of interrelationships among discourse: "[Examine] existing scholarship on child-raising advice and mothering as well as an analysis of literacy advice to mothers in the Nineteenth Century" ( p. 47).

4. Identifying the discursive strategies that are deployed: "[Attend] to how the discourses of intensive mothering, domestic pedagogy and the normal family are kept in place all circulated through literacy advice...[I] looked for ways in which both mothering practices and literacy practices were compared, distinguished and/or divided" (p. 48).

5. Looking for absences and silences: "[s]trategies of substitution...[I] looked for inherent contradictions in advice which often suggested silences" (p. 48).

6. Looking for resistances and counter-discourses: "The analytic strategy of multi-vocality was useful in identifying resistance and counterdiscoursesin advice...another strategy....was to include in the analysis texts outside of the mainstream of popular culture or commercial publishing" (pp. 48-49).

7. Identifying the effects of discourse: "[T] his step refers to analyzing the implications of discourse in terms of how power and knowledge are valued and circulated" (p. 49).

8. Situating the analysis in the broader discursive context: "Situating discourse analysis within a broader oeuvre, or terrain, is a central component of a Foucauldian approach" (p. 50).

9. Attending to the limitations of the research, your data and sources: "[D]ata used in this study represent but one small window into diverse and complex set of practices and experiences" (p. 50).

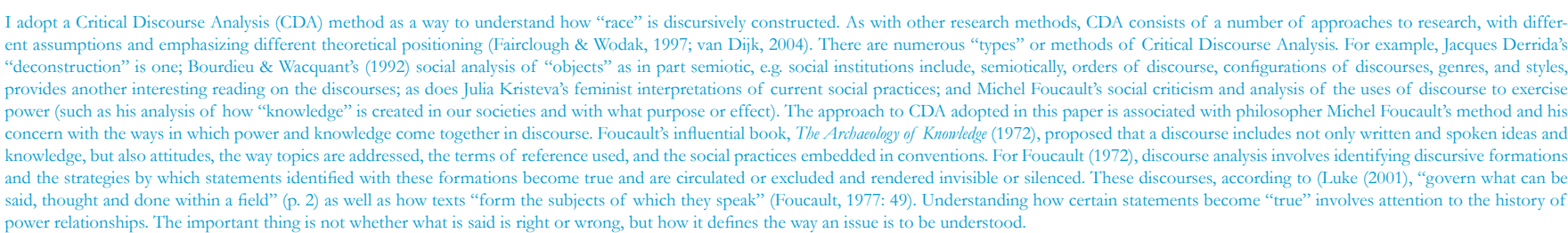

power relationships. The important thing is not whether what is said is right or wrong, but how it defines the way an issue is to be understood. 
to the limitations of the research indicating the significance of the data presented within a diverse and complex set of practices, experiences, and contexts [8]. Figure I below summarize steps taken utilizing Carabine' (2001) framework.

A Critical Discourse Analysis (CDA) process began with a critical review of literature or what Carabine (2001) frames as the "scientific" reification of a phenomenon (and in this case the reification race and health disparities in epidemiological and public health discourse). Chiefly, the CDA examined how knowledge about health disparities is liked with race. Then, an analysis of information derived from three public health survey instruments in Brazil was summarized to elucidate the limitations of the discourse relating to health disparities and race. Thus, the content, language, and structure of the 2003 World Health Survey (WHS), the 2006 Brazilian National Household Sample Survey (BNHSS) and the Brazilian Oral Health Survey (BOHS) were analysed to understand particular ways racial ${ }^{2}$ categories were used and/or conceptualised.

The WHS is a population-based survey conducted in 2003 as part of a World Health Organization (WHO) project aimed at collecting information on populations' health status and health system performance by means of household surveys. According to de Vasconcellos, Nascimento Silvaand Szwarcwald (2005), the WHS was coordinated by the Oswaldo Cruz Foundation with support from the Brazilian Institute of Geography and Statistics (IBGE) ${ }^{3}$. The WHS was conducted between January and September 2003 and included a national sample of five thousand randomly selected households in a set of 250 census tracts in 188 municipalities (or counties).

In addition to the WHS, the 2006 Brazilian National Housebold Sample Survey (BNHSS) was analyzed. Like the WHS, the BNHSS is part of a national strategy to collect, analyze, and disseminate country specific and representative data on housing characteristics, family well-being, immigration processes, health, nutrition, fertility, and educational attainment, labour market and employment, health and well-being, and food consumption patterns. BNHSS is a cross sectional survey and was first introduced in 1967 and subsequent surveys were collected every year except years of the national census. The demographic and economic information includes age, gender, education, race, household income and labour force status. Additionally, the BNHSS evaluated the use of health services by individuals in terms of visits to health care providers, the use of drugs and other medications, and systems response to diverse health needs of populations.

The final survey to be analyzed was the 2003 Brazilian Oral Health Survey (BOHS). The BOHS was administered by the IBGE and in 2003 it was the largest epidemiological oral health survey conducted in Brazil. The BOHS collected epidemiological information on factors associated with negative self-rated oral health (i.e. tooth loss, fluradization, dental pain, etc.). Independent variables included geographical localization, gender, skin color/"race," per capita income, education gap, dental service utilization and fluoridated water supply at the local level $[4,29]$. The data collection was also cross-sectional and it involved data collectors (survey facilitators) who were trained by the IBGE in epidemiological oral health surveys following diagnostic criteria set by World Health Organization (WHO). Table 1 below details the three surveys' focus, sample sizes, and year of administration.

\section{Findings}

Brazil grapples with assessing racialized health outcomes through survey enumeration. The push and pull to collect or not to collect racial data stems from the history of survey enumeration. With health disparities projected to increase amongst racialized groups, the World Health Survey was introduced to measure health determinants as they relate to socio-demographic factors. The survey instrument originally proposed by the World Health Organization and later the IGBE reviewed, modified, and adapted the survey to fit the Brazilian context. The refined WHS instrument included modules related to coverage of health programs, access and utilization of health services, health informatics including health status determinants such as gender, race/skin color, education, and income. The "race" question in the WHS asked respondents' to indicate their skin color or racial categories: "A sua cor ou raça e"; in which seventeen color-based identity markers were suggested to the respondents. Table 2 lists racial categories as framed in the WHS highlighting the construction of a color scheme for identification purposes.

The "race affiliation" schema in the WHS therefore consisted of 17 identifications that include: White (Branco), Moreno, Brown (Pardo), Moreno Claro, Black (Preto), Negro, Claro, Mulato, Escuro, Moreno Escuro, Canela, Moreno Brown (Moreno Pardo), Castanho, Mestiço, Amarelo, Indígena, and Others). These identifications are based on the Brazilian socio-political history of classifications as indicated in the census enumeration process. Data on respondents" color and "race affiliation" were collected in three different ways in the WHS. Prior to initiating the interview, interviewers classified respondents according to the census format described earlier in the chapter using the five color categories. Then, towards the beginning of the questionnaire, interviewers asked respondents to self-identify in an open-ended question. There is interplay between state-formed objectified categories and selfidentified descriptions. There is generally this similarity between the two contexts (just as there is generally an historically shifting state interest in shaping race classifications), but then what is different in each context is how "skin color" rather than ethnicity conflate "race" in Brazil.

Generally, the categories of "black" (preto), "white" (branco), and "yellow" or "Asian" (amarelo), and "pardo" (brown) are suggested as categories in the WHS. Pardo (which literally means brown) is more of an official term used to refer to multiracial individuals, particularly mulattoes. A vernacular term such as moreno (yellow), however, is a euphemism that is be used to describe a wide variety of "brunette" phenotypes, including those individuals who are designated as preto, pardo, or branco (if the latter have dark hair and eyes). Although "Moreno" and "negro" translate as "brown," the Portuguese term pardo literally refers to an "unflattering, arid grayish brown color that in popular parlance would rarely be used to describe one's self (Sheriff, 1997). Furthermore, according to

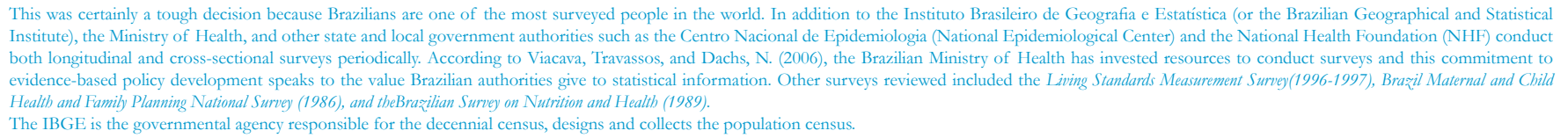

Health and Family Planning National Survey (1986), and theBrazilian Survey on Nutrition and Health (1989. 
Table 1. Description of the WHS ${ }^{4}, \mathrm{BNHSS}^{5}$, and the $\mathrm{BOHS}^{6}$ in Brazil.

\begin{tabular}{|c|c|c|c|}
\hline Survey & Year & Topic & Sample Size(household) \\
\hline WHS & 2003 & Health determinants, health status and health system utilization & 4961,00 \\
\hline BNHSS & 2006 & Demographic, economic, and health information & 118,590 \\
\hline BOHS & 2003 & Oral and dental health & 108,921 \\
\hline
\end{tabular}

Table 2: Categories used in the WHS (2003) to signify "Racial identity"

\begin{tabular}{|c|c|}
\hline \multicolumn{2}{|c|}{ "Racial Categories" } \\
\hline White (Branco) & Escuro \\
\hline Moreno & Moreno Escuro \\
\hline Brown (Pardo) & Canela \\
\hline Moreno Claro & Moreno Brown (Moreno Pardo) \\
\hline Black (Preto) & Mestiço \\
\hline Negro & Others \\
\hline Claro & \\
\hline Indígena (Indigenous) & \\
\hline Mulato & \\
\hline Source: WHS (2003) & \\
\hline
\end{tabular}

Piza and Rosemberg (1999), pardo originated as a catch-all term for persons who did not appear to fit the black, white, and yellow classifications, and it thus became a category that encompassed all intermediate and mixed categories.

Unlike the term "black" used in other contexts (i.e. USA, Canada, South Africa and so forth), which can represent an identity encompassing all African descendants originating from diverse geographical locations, Brazil adopted the word preto to strictly refer to the "darker end of a color continuum" and thus denotes a totally different meaning to other words such as pardo or moreno (Sansone, 1997a) ${ }^{7}$. The WHS survey instrument also utilised additional categories that, according to Piza \& Rosemberg (1999), are widely used in the everyday life vernacular in Brazil. The WHS adopted several distinctions to differentiate amongst African descendants in addition to the official IGBE: "White, Black, Asian, Brown, and Indigenous"racial categorizations and distinctions. For example, in the WHS terms such "Preto" and "Pardo" to collectively refer to the Afro-Brazilian population instead of terms such as: "negro," "Afro-Brasileiro," or "Afro-descendente" were used $^{8}$. A deeper observation of the survey language, structure, and content of the WHS reveals that that the "Branco" and "Pardo" categories are notoriously inflated, and the "Preto" diminished.

Additionally, the "Branco" identification remains constant, while identifier the "Preto" and "Pardo" identifications are diversified. Due perhaps to political reasons, the "pardo" and "preto" and even "negro" identifications are separated and perhaps if there were to be combined into "negro" as some in the Afro-Brazilian civil rights movement suggest, then the information would tell a different story. Another observation in the design of the survey is the ordering of the response categories. Telles and Lim (1999) have investigated this issue especially in the Brazilian Census context. These authors have concluded that in most surveys there is a tendency to present the response categories in a color continuum from "white" to "black." This structure tends to communicate the message of value and in most cases, reveal how the spectrum of the color continuum is hierarchized within the Brazilian case. For example, Telles (1999) and Telles and Lim (1999) observed a phenomenon referred to as "branqueamento" or the tendency for to self-classify as "white. Thus, in surveys most African descends tend to self-classify as "white" or "mulatto" and not "preto" (black) in most Brazilian surveys. Telles and Lim (1999) In their analysis of race categories used in Brazilian Censuses, further observed that the different 'shades of blackness' are institutional mechanisms of power and control in that "pretos" tend to self-classify as mulattos, while the differences found in the shares of "preto" and "mulattos" self-classify as "whites." Thus, the "closer" one can identify with the "white" category as defined in surveys, the more likely you will identify as "white."

Telles and Lim (1999) observations raises several observations. First, it seems that the "choice" to self-identify as "white" or "black" in surveys has material consequences. There seems to be a dimension that is far more material to self-identify as "white" in Brazil and this perhaps could be explained historically since slavery. Second, decades of miscegenation has created a society in which skin color determines social, political, and economic stratification and a color continuum (in which "whiteness" is desired and blackness is less desired). This has become embedded in the fabric of Brazilian society and reinforced by messages given in the survey enumeration process. Thus, if the "branqueamento" phenomenon truly exists as Telles and Lim (1999) have observed, then self-classifying as "white" because being "white" represents material or socioeconomic rewards, most Afro-Brazilians don't stand a chance of their disadvantage being addressed. Thus, how does this classification scheme address the material disadvantage category ("Pesquisa Odontológica de Acão Coletiva - POAC)" at the Annual Meeting of the "Sociedade Brasileira de Pesquisa Odontológice" SBPqO) (Brazilian Society for Dental Research), the Brazilian Division of the International Association for Dental Research. The Brazilian Oral health Survey is one of a number of surveys in Brazil that assesses oral and dental health. For a thorough analysis also see Zorzetto R, Razzouk D, Dubugras MT, Gerolin J, Schor N, Guimarães JA et al. (2006). The scientific production in health and biological sciences of the top 20 Brazilian universities. Brazilian Journal of Medical Biological Residence, 39(12), pp. 1513-20. According to Sansone (1997a) in "The New Blacks from Bahia: Local and Global in Afro-Bahia" Identities. 3: 4: 457-493, preto in popular parlance carries negative connotations when used by third persons. In English, the tem: "Black," "African Brazilian" and "people of African descent" refer to this same sum of the two groups. 
of those it is intended to foregrounds? Having said that, classifications schemes that attempt prescribe identification markers might essentialize and reduce identifications to an extreme of underrepresenting and underestimating differences between groups.

The second survey examined was the Brazilian National Household Sample Survey (BNHSS) or Pesquisa Nacional por Amostra de Domicilios (PNAD). Like the WHS, the BNHSS is part of a national strategy to collect, analyze, and disseminate data on demographic and economic information of Brazilians in numerous areas including family well-being, immigration processes, health, nutrition, fertility, and educational attainment, labour market and employment, health and well-being, and food consumption patterns. The collection instrument was the direct interview with paper forms [16]. BNHSS also assessed information on skin color/"race," age, and gender. Unlike the WHS, the question about race: what is your race?, conformed to the IGBE typology that includes: "White" (Branca), "Black" (Preto), Yellow (Amarela), Brown (Parda), and Indigenous (Indígena). The BNHSS treatment of the "race" question pointed to two major observations.

First, racial categories are expressed as single color-coded variables whereby a respondent is encouraged to assign himself/herself a category in a color continuum. Secondly, from that "chosen" classification, racial categories presented in the BNHSS restrict the ability of respondents to represent a multi-faceted nature of selfidentity. The BNHSS survey instrument resorted to the IBGE frameworks of racial identification, where prescribed categoties of "White" (Branca), "Black" (Preto), Yellow (Amarela), Brown (Parda), and Indigenous (Indígena) were choices regardless of how individuals might self-identify. Agreeing with Telles (1992) skin color not race has become the significant marker identification in the BNHSS, impliying that skin color' is the default language through which race is discursively produced. Figure 2 below describes five classifications based on skin color used in the 2006 Brazilian National Household Sample Survey (BNHSS).

The final survey instrument analyzed was the 2003 Brazilian Oral Health Survey (BOHS). The BOHS was the largest epidemiological oral health survey conducted in Brazil evaluated epidemiological information on factors associated with negative self-rated oral health (i.e. tooth loss, fluradization, dental pain, etc.). The IGBE identification framework on race and skin color also was observed as a prevailing mode of classification. Like the BNHSS, the BOHS conformed to the "White" (Branca), "Black" (Preto), Yellow (Amarela), Brown (Parda), and Indigenous (Indígena) conceptualization. Table 3 below describes the racial categories used in the BOHS.

Unlike the WHS and the BNHSS that asked the question at the end of the survey in the demographic sessions, the BOHS asked the racial identification question at the beginning. This strategy is very important in two ways. First, this conditions survey respondents to think about race from the onset. Thus the association between skin color with dental oral health as a core issue of investigation was illuminated. Second, what is also striking with the identification categories in the BOHS is that the only marker that seems not be color-coded is the indigenous category. The issue of not color-coding indigenous populations in Brazil is very political and underscores the assimilationist policies that indigenous Brazilians have been fighting for centuries. Further, it also at least indirectly marks a cultural category and positions Indigenous people as an "exception" in that in their case, race $=$ color $=$ cul- ture). Clearly, the ancestry and ethnic discourse within indigenous identity politics in Brazil is at odds with the racialist government discourse. This is also seen in the BNHSS and the WHS.

These observations confirm the difficulties many critical race theorists have noted with inconsistent and frequently unclear systems of classification. In general, it appears that the conformity to the framework prescribed by the IGBE limit what we can know about oral health that impacts the Brazilian population. It would be very interesting to know, for instance whether classification decisions had been developed with sufficient evaluation of the underlying social and geographic reality. This practice of classifying human populations through racial categories as single variables highlights pre-conceived assumptions about the realness of such social contracts, as opposed to just an open question whose responses are then arranged according to the more meaningful common identities. In the Brazilian surveys analyzed, a major problem of what this information means came to the surface. The categories used in all the surveys analysed proved not to reflect the complex heterogeneity found within each group. Table 4 summarizes the conceptualization of identification markers in the three national surveys analyzed.

This confirms the results of studies conducted by Connolly and Gardener (2005), Agyemang et al. (2005), and Aspinall (2003) whereby efforts to reach a consensus between surveillance statistics and reliance of meaningful categories comprises a highly contested issue in the arena of identity politics [35]. Furthermore, it is clear from the data analysed in this chapter that such categories are always contextual to a country and moment in time [30], according to each society's response to their own particular historical processes of ethnogenesis [12]. For example, the racial categories of African descendents who might not prescribe to being labelled pardo, preto, and mulato in Brazil offer particularities of the construction and production of race in each country. In Brazilian surveys, "race affiliation" refers primarily to appearance (skin color) rather than descent or place of origin or ethnicity/culture. As seen in the examples of Brazilian surveys discussed in this paper, respondents are asked directly to indicate their "color or race" ("A sua cor ou raça e") and five response categories use color terms (Branca-white; Amarela-yellow), implying a gradation of color (Preta, Parda — darker and lighter brown), and identify Indigena status. Brazil's reliance on one question alone with skin color-coding raises the important question of how Brazilian survey designers (i.e. IGBE) understand human difference.

\section{Discussion}

The CDA analyses of the use of racial categories in survey instruments in Brazil reveal both the importance and limitation of utilizing such racial categories in epidemiology. On one hand, assessing race can be important tool that helps in the understanding of why diverse populations experience different health outcomes (i.e. racial categories indicate whether the sample population being studied is representative of a broader population; identify health disparities facing minoritized populations; and suggest effective interventions). On the other hand, the existing racial classifications suffer from numerous weakness such as lack of agreement on the meaning and definition of race as a concept and categories, dominance of quantitative approaches that depend on aggregating large numbers of individuals into small number of analytical categories to attain "significance", and lack of contex- 
Figure 2. Racial Categories used in the Brazilian National Household Sample Survey, 2006.

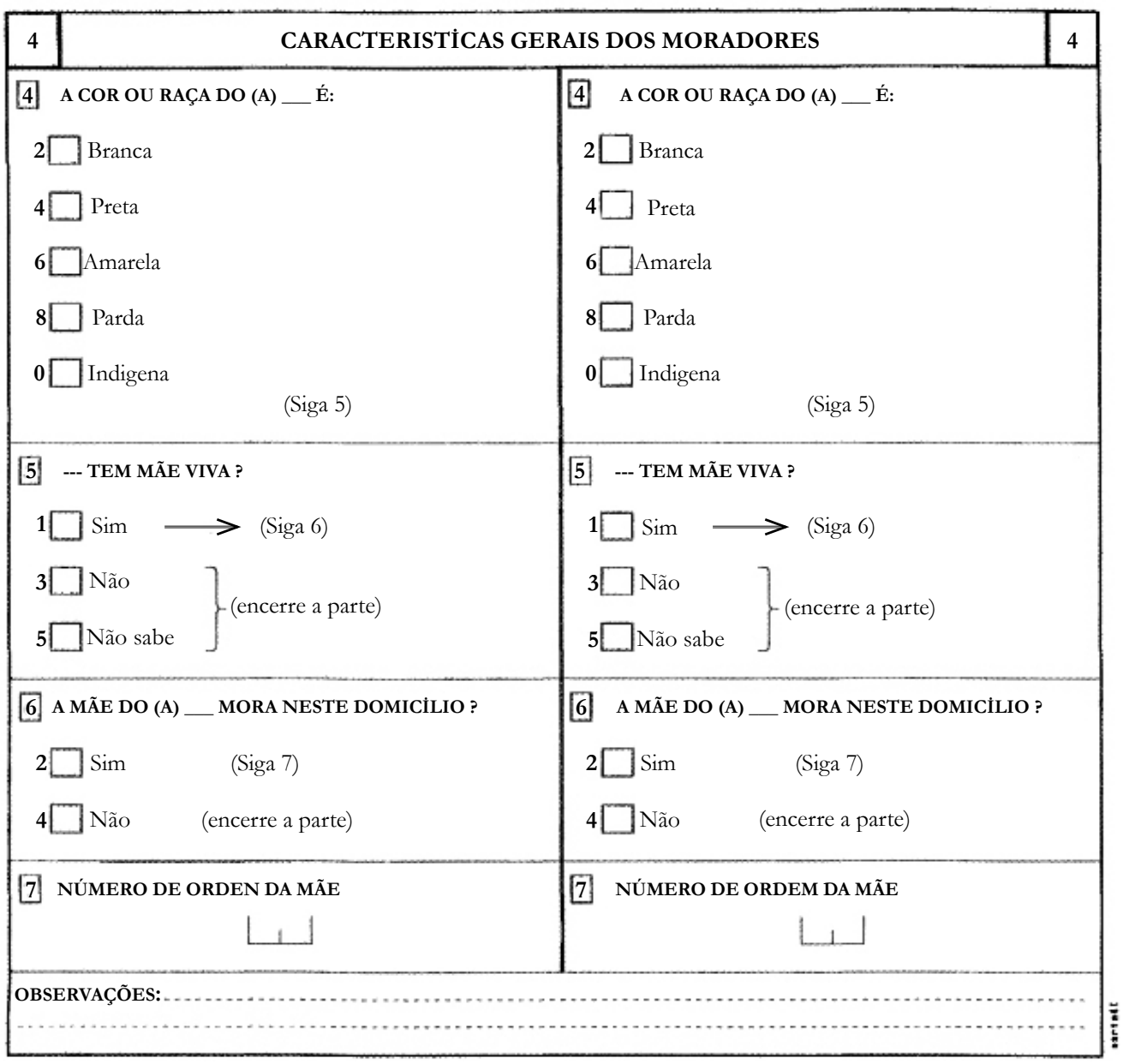

Table 3. "Race" Categories used in the Brazilian Oral Health Survey, 2003.

\begin{tabular}{|c|}
\hline Racial Categories \\
\hline White (Branco) \\
\hline Brown (Pardo) \\
\hline Black (Preto) \\
\hline Amarelo (Asian descent) yellow \\
\hline Indígena (Indigenous) \\
\hline Others \\
\hline
\end{tabular}

Source:BOHS, 2003

Table 4. Conceptualization of Identity Markers in three Surveys in Brazil.

\begin{tabular}{|c|c|c|c|}
\hline \multirow{2}{*}{ Primary or Secondary Term: } & \multicolumn{3}{|c|}{ BRAZILIAN } \\
\cline { 2 - 4 } & \multicolumn{3}{|c|}{ SURVEYS } \\
\cline { 2 - 4 } & WHS & BNHSS & BOHS \\
\hline Race & $\mathrm{X}$ & $\mathrm{X}$ & $\mathrm{X}$ \\
\hline Skin color & $\mathrm{X}$ & $\mathrm{X}$ & $\mathrm{X}$ \\
\hline Minority Status & - & - & - \\
\hline Culture & - & - & $\mathrm{X}$ \\
\hline Ethnicity & - & - & - \\
\hline Ancestry (including indigenous) & $\mathrm{X}$ & $\mathrm{X}$ & $\mathrm{X}$ \\
\hline Nationality & - & - & - \\
\hline Tribe & - & - & - \\
\hline Symbols: - : not applicable & $\mathrm{x}:$ applicable \\
\hline
\end{tabular}


tual rigor in understanding differences in health-related outcomes. Thus, when race is narrowly defined and conceptualized, as seen in the surveys analyzed, differences in attitudes and values regarding health behaviors of individuals and groups are often ignored. To summarize, the surveys examined in this paper uses race as a single variable (i.e. that of a racialized group into which the individual self-assigns himself/herself from a classification of a reduced number of strata). This restricts the ability to represent the characteristics of the multi-faceted nature of self-identity beyond prescribed identities. As seen throughout the paper, epidemiological assessments need to include the heterogeneity of identity so that culturally and contextually sensitive conclusions can be drawn and allow for a proper analysis of the health determinants of racialized and minoritized groups. There is a need therefore, for more complex ways for self-identification that problematizes orthodox prescribed categories of human stratification in survey enumeration.

Secondly, the instruments adopt pre-conceived notions of difference rooted in positivistic classification schemas to facilitate the reproduction and comparison of the resulting statistics over time and between different sources, as opposed to the fluidity and heterogeneity of identities. ( $\mathrm{Im}$ ) precision in definition of minoritized and racialized groups is compounded by challenges in data collection, data analysis, and interpretation, along with the positivistic approach that shapes epidemiological research regimes. A third problem comes with the consensus in within the survey instruments examined that respondents have a "choice" in selecting pre-determined set of racialized categories. The illusion of choice into racial schemas subsumes a stagnant idea of identity across time and space. Thus, as a result of the "choice" into a pre-determined set of racialized categories, the classifications of individuals conform in time and space, since perceptions of individual and social identity are assumed not to change over time except when categories are re-classified.

The social construction of race, as a concept and as structure leads to specific discourses of understanding about human difference, which perpetuates what Thomas Teo (2008) frames as "epistemological violence" in which the research process construct the 'other' implicitly or explicitly allowing interpretations of data to be presented as 'knowledge' when, in fact, harm is inflicted through them. The findings presented in this paper show that codified concepts and an implied logic are utilized in constructing epidemiologic surveys, conveying messages that appear unproblematic. The discourse is further facilitated by epidemiologic analyses in the academe that reify the notion of race and legitimize its everyday use as a valid concept. The continued uncritical use of race not only reproduces research hegemony ${ }^{9}$, but has policy and practice implications at local, national, and global levels. And as such must be diligent and clear in their reporting of both primary and secondary analyses and intentionally record and discuss why race is being used, how it is being assessed, and what the potential findings based on its use may imply.

\section{Conclusion}

This paper maintains that epidemiological and public heath knowledge about race and health disparities is a Foucauldian discursive formation with its own particular objects of knowledge, producers of discursivity, and criteria for what knowledge is valued or devalued. This builds on works of Bashi (1998), Bonilla-Silva (2003), Teo (2008), Burchard, Ziv, Coyle et al. (2003), Epstein, (2004), and Lee (2005), who identified academic "discourses" that organize human difference in specific ways, creating classificatory systems of being and becoming. As demonstrated in the paper, race discourse in survey instruments is shaped by all kinds of narratives, experiences, positions, assumptions that in turn prescribe and ways of knowing and doing. Therefore, how epidemiologists and public health researchers use, conceptualize, measure, and talk about race is immensely consequential. The routine (re)production of epidemiological information on health disparities in national population health surveys and its use of racial categories provides a methodological dilemma in community medicine and epidemiology.

Often presented as a means of explaining the persistence and maintenance of gaps in health status across racialized groups, the concept of race has enjoyed an uncritical advantage in health discourse. Faced with the persistence of poorer health outcomes within and between groups, most epidemiologists and medical sociologists rationalize the use racial categories indicating that the synergies produced by the discourse will entice governments, communities, and individuals to intervene and address risk factors proactively. Public health researchers and epidemiologists alike often point to the spectre of the usual suspects in the discourse: that is, a disproportionate preference to poor health, a lack of truly equal access to good healthcare, and a breakdown in effective interactions between racialized groups and the health care system; all factors framed as indicative of the fecundity of race as a central culprit in explaining health disparities. This paper demonstrates that when race is narrowly defined and conceptualized, differences in attitudes and values regarding health behaviours of individuals and groups are often ignored and silenced. Thus, the technology of epidemiological enumeration as practiced in medicine, public health, and epidemiology (re)produces and normalizes discredited racial classification schemes based on biology, shaping the discourse in particular ways for specific purposes, and thus pointing to the socio-political incubation, regurgitation, and recycling of a discredited discourse.

\section{References}

[1]. Agyemang C, Bhopal R, Bruijnzeels M (2005) Negro, Black, Black African, African Caribbean, African American or what? Labeling African origin populations in the health arena in the 21 st century. J Epidemiol Community Health 59(12): 1014-1018.

[2]. Aspinall PJ (2001) Operationalising the collection of ethnicity data in studies of the sociology of health and illness. Sociology of Health \& Illness 23(6): 829-862.

[3]. Aspinall PJ (2003) The conceptualisation and categorisation of mixed race/ ethnicity in Britain and North America: Identity options and the role of the state. International Journal of Intercultural Relations 27(3): 269-296.

[4]. Barbato PR, Peres MA (2009) Tooth loss and associated factors in adoles-

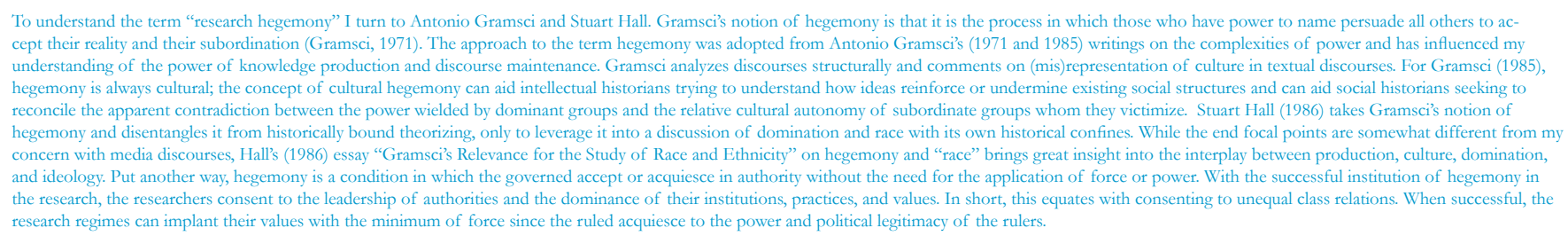


cents: a Brazilian population-based oral health survey. Rev Saude Publica 43(1): 13-25.

[5]. Bashi V (1998) Racial categories matter because racial hierarchies matter: A Commentary. Ethnic and Racial Studies 21(5): 959-968.

[6]. Bonilla-Silva E (2003) Racism without Racists: Color-Blind Racism and the Persistence of "Racial" Inequality in the United States. (2nd edtn), Rowman \& Littlefield Publishers, Inc., USA.

[7]. Burchard EG, Ziv E, Coyle N, Gomez SL, Tang H, et al. (2003) The importance of race and ethnic background in biomedical research and clinical practice. N Engl J Med 348(12): 1170-1175.

[8]. Carabine J (2001) Unmarried motherhood 1830- 1990: A genealogical analysis. Discourse as Data: A Guide for Analysis. Sage Publications, London. 267.

[9]. Connolly H, Gardener D (2005) Who are the 'Other' ethnic groups? Social and Welfare Reports. Office for National Satistics. London. Available at: http://www.statistics.gov.uk/articles/nojournal/other_ethnicgroups.pdf.

[10]. Crews DE, Bindon JR (1991) Ethnicity as a taxonomic tool in biomedical and biosocial research. Ethn Dis 1(1): 42-49.

[11]. Epstein S (2004) Bodily differences and collective identities: the politics of gender and race in biomedical research in the United States. Body Society 10(2-3): 183-203.

[12]. Eriksen TH (2002) Ethnicity and Nationalism. (2nd edtn), Pluto Press, London.

[13]. Essed P (1991) Understanding Everyday Racism: An Interdisciplinary Theory. Sage Publications, London.

[14]. Fairclough N, Wodak R (1997) Critical discourse analysis. Discourse as Social Interaction. Sage Publications, London. 258-284.

[15]. Fairclough N (2003) Analyzing Discourse: Textual Analysis for Social Research. Routledge, London.

[16]. Ferreira FH, Leite PG, Ravallion M (2010) Poverty reduction without economic growth: Explaining Brazil's poverty dynamics, 1985-2004. Journal of Development Economics 93(1): 20-36.

[17]. Froehlich TE, Bogardus ST Jr, Inouye SK (2001) Dementia and race: Are there differences between African Americans and Caucasians? J Am Geriatr Soc 49(4): 477-484.

[18]. Foucault M (1972) The Archaeology of Knowledge. Pantheon Books, New York.

[19]. Foucault M (1981) The order of discourse. In Untying the text: a post-structuralist reader. Routledge \& Kegan Paul, Boston. 48-78.

[20]. Gollogly L, Momem H (2006) Ethical dilemmas in scientific publications: pitfalls and solutions for editors. Rev Saude Publica 40(Spec no): 24-29.

[21]. Gramsci A (1971) Selections from the Prison Notebooks. International Publications, New York.

[22]. Gramsci A (1985) Selections from Cultural Writings. Harvard University Press, Cambridge.

[23]. Hall S (1986) Gramsci's Relevance for the Study of Race and Ethnicity. Journal of Communication Inquiry 10(2): 5-27.

[24]. Hegarty V, Burchett BM, Gold DT, Cohen HJ (2000) Racial differences in use of cancer prevention services among older Americans. J Am Geriatr Soc 48(7): 735-740.

[25]. Kessler RC, Mickelson KD, Williams DR (1999) The prevalence, distribution, and mental health correlates of perceived discrimination in the United States. J Health Soc Behav 40(3): 208-230.

[26]. Krieger N (2004) Data, "race," and politics: a commentary on the epidemiological significance of California’s Proposition 54. J Epidemiol Community Health 58(8): 632-633

[27]. Lee SS (2005) Racializing drug design: implications of pharmacogenomics for health disparities. Am J Public Health 95(12): 2133-2138.

[28]. Luke A (2001) What happens to literacies old and new when they're turned into policy? Conference on New Literacies and Digital Technologies. University of Georgia: University of Georgia.

[29]. Martins AM, Barreto SM, Pordeus IA (2009) Objective and subjective factors related to self-rated oral health among the elderly. Cad saude Publica 25(2): 421-435.

[30]. Peach C (2000) Discovering white ethnicity and parachuted plurality. Progress in Human Geography 24(4): 620-626.

[31]. Edith P, Rosemberg F (1999) Color in the Brazilian Census. From Indifference to Inequality: Race in Contemporary Brazil. Pennsylvania State University Press, University Park, PA. 37-52.

[32]. Pan American Health Organization (2007) Health Situation Analysis Trend Summary. Health Analysis and Statistics Division, PAHO.

[33]. Popay J, Thomas C, Williams G, Bennett S, Gatrell A, et al. (2003) A proper place to live: health inequalities, agency and the normative dimensions of space. Soc Sci Med 57(1): 55-69.

[34]. Sansone L (1997) The New Politics of Black Culture in Bahia, Brazil. The Politics of Ethnic Consciousness. St. Martin's Press, New York. 277-309.

[35]. Skerry P (2000) Counting on the Census? Race, Group Identity, and the Evasion of Politics. Brookings Institution Press, Washington, DC.

[36]. Smith GD, Bartley M, Blane D (1990) The Black Report on Socio-Economic Inequalities in Health 10 Years on. BMJ 301(6748): 373-377.

[37]. Van Dijk TA (1995) Discourse Semantics and Ideology. Discourse \& Society 6(2): 243-289.

[38]. Van Dijk TA (1997) Discourse as social interaction. Sage Publications, London.

[39]. Van Dijk TA (2001) Principles of Critical Discourse Analysis. In Discourse Theory and Practice: A Reader. Sage Publications, London.

[40]. Telles EE (1992) Residential Segregation by Skin Color in Brazil. American Sociological Review 57(2): 186-197.

[41]. Telles EE (1999) Ethnic Boundaries and Political Mobilization among African Brazilians: Comparisons with the US Case. In Racial Politics in Contemporary Brazil. Duke University Press, North Carolina. 85-93.

[42]. Telles EE, Lim N (1998) Does it Matter Who Answers the Race Question? Racial Classification and Income Inequality in Brazil. Demography 35(4): 465-474.

[43]. Teo T (2008) From Speculation to Epistemological Violence in Psychology: A Critical-Hermeneutic Reconstruction. Theory Psychology 18(1): 47-67.

[44]. Vasconcellos MTL, Silva PLN, Szwarcwald CL (2005) Sampling design for the World Health Survey in Brazil. Cad Saúde Pública 21(Suppl 1): S89-99.

[45]. Viacava F, Travassos C, Dachs N (2006) Inquéritos nacionais em saúde no Brasil. Rev CS Col 11(4): 860-860.

[46]. World Health Organization (1997). The Jakarta Declaration on Leading Health Promotion into the 21st Century. World Health Organization, Geneva. Also available at www.who.int/hpr/NPH/docs/jakarta_declaration_en.pdf

[47]. WHO (World Health Organization) (1998). Social Determinants of Health The Solid Facts. Copenhagen: World Health Organization Regional Office for Europe. Also available at www.who.dk/document/e59555.pdf

[48]. WHO (World Health Organization) (2004). Priorities to Take Forward the Health Equity Agenda: Report from the Task Force on Health System Research Priorities for Equity in Health. WHO Regional Office for Europe, Copenhagen.

[49]. Zorzetto R, Razzouk D, Dubugras MT, Gerolin J, Schor N, et al. (2006) The scientific production in Health and Biological Sciences of the top 20 Brazilian Universities. Braz J Med Biol Res 39(12): 1513-1520. 